\title{
Las relaciones entre nacionalismo y cosmopolitismo*
}

\author{
Daniel Chernilo
}

Loughborough University

d.chernilo@lboro.ac.uk

\section{Resumen}

El presente artículo estudia las relaciones entre nacionalismo y cosmopolitismo y plantea comprender ambos conceptos como posiciones mutuamente interrelacionadas antes que contrapuestas. Estudiar sociológicamente las versiones modernas del nacionalismo y el cosmopolitismo requiere considerar, filosóficamente, los momentos de particularidad y de universalidad que hay en cada uno. Mientras que el particularismo del nacionalismo depende de su capacidad para proveer de un sentido de clausura a nuestras identidades sociales y políticas, el universalismo en el cosmopolitismo se centra en una noción inclusiva de la humanidad. Pero el cosmopolitismo tiene también un momento de particularidad en términos de la autorreflexión sobre "nuestras» tradiciones y de duda sobre "nuestras» creencias más sentidas. Finalmente, el momento universalista del nacionalismo se centra en el principio de autodeterminación individual y colectiva que, cuando se afirma para el propio grupo, no puede negarse normativamente a otros.

Palabras clave: cosmopolitismo; globalización; nacionalismo; particularismo; sociología; universalismo.

* Se han presentado versiones preliminares de este trabajo en la conferencia de la Asociación Europea de Sociología, en Turín, en agosto de 2013; en el seminario «Procesos Transnacionales y Estado Moderno", en la Universidad de Trier, en abril de 2014; en la conferencia «Poder, Cultura y Economía», en la Universidad de Tampere, en agosto de 2014, y en el seminario titulado «Identidades cosmopolitas», en la Universidad Autónoma de Barcelona, en noviembre de 2014. Mis agradecimientos a los organizadores y a los participantes de estos eventos por sus comentarios, críticas y sugerencias. El último borrador de este trabajo se benefició enormemente de la lectura atenta de Marco Antonsich, Esperanza Bielsa y Aldo Mascareño. 
Abstract. Relations between Nationalism and Cosmopolitanism

This article studies the relationship between nationalism and cosmopolitanism and suggests that they may be understood as mutually interrelated rather than opposed positions. Studying the modern versions of nationalism and cosmopolitanism from a sociological point of view requires also, philosophically, considering the moments of particularity and universalism in each of them. Whereas the particularism of nationalism depends on its capacity to provide our social and political identities with a sense of closing, the universalism of cosmopolitanism is focused on an inclusive notion of humanity. But cosmopolitanism also has a moment of particularism in terms of self-reflection on 'our' traditions and of doubt about 'our' deepest beliefs. Finally, the universalist moment of nationalism focuses on the principle of individual and collective self-determination, which cannot be normatively denied to others when accepted for one's own group.

Keywords: cosmopolitanism; globalization; nationalism; particularism; sociology; universalism.

En una conferencia reciente sobre cosmopolitismo, Jürgen Habermas (2014) inicia su intervención comentando que le resulta incómodo usar un término que se ha convertido en objeto de veneración algo ritualista. Señala, allí también, que la idea de cosmopolitismo ha devenido algo anticuada, algo que no deja de sorprender, puesto que ello nunca pareció molestar especialmente a Habermas en sus escritos anteriores. Pero el centro de su argumento es que el cosmopolitismo es ya una noción demasiado débil para comprender la Realpolitik de la vida internacional contemporánea. En vez de cosmopolitismo, Habermas sugiere entonces que nos concentremos en el concepto más complejo de «constitucionalización del derecho internacional» ${ }^{1}$. Si bien Habermas no fue nunca partidario de las versiones más radicales del cosmopolitismo, esta posición demuestra un cambio de opinión si se la compara con sus trabajos sobre el tema realizados durante las últimas dos décadas (Habermas, 1999, 2001a). Habermas postulaba allí una versión menos estridente y más sofisticada sobre las tendencias globalizantes que, hacia el cambio de milenio, parecían estar transformándolo todo. Aun así, es posible que este cambio parcial de postura refleje también una autocrítica a la forma en que él también se vio envuelto en el optimismo algo ingenuo de los discursos globalizadores del cambio de siglo (Albrow, 1996; Castells, 1996; Scholte, 2000; Urry, 2000).

Pero los escritos de Habermas nos ofrecen un camino alternativo para reevaluar los desafíos de la «constelación posnacional» contemporánea: la importancia de comprender las relaciones entre nacionalismo y cosmopolitismo, incluso si tales reflexiones se mantuvieron en un nivel más bien implícito en su propio trabajo (Chernilo, 2007: 151-158, 2010: 175-199). Desde el punto de vista de

1. Habermas menciona en especial las obras de Hauke Brunkhorst (2014) y Gunter Teubner (2012). He discutido sobre los elementos centrales de este nuevo constitucionalismo sociológico en Chernilo (2014b). 
una historia conceptual, Habermas revisó los escritos cosmopolitas de Kant y discutió los fundamentos normativos de la democracia moderna a nivel estatal con miras a su potencial expansión al nivel transnacional. Desde el punto de vista de la observación de eventos sociales y políticos, su interés se centró en asuntos como el futuro y el déficit democrático de la Unión Europea, la globalización económica y la doctrina de Bush y Blair de la "guerra contra el terrorismo» (Habermas, 2001b, 2003, 2006). El uso del prefijo pos- en su conceptualización de la constelación posnacional - y este argumento vale también para sus trabajos sobre pensamiento posmetafísico- expresa una ambigüedad fundamental (Chernilo, 2013b). En ocasiones, el argumento parece indicar la tesis fuerte de que el nacionalismo (y la metafísica) son asuntos del pasado sin potencial práctico o normativo en el presente. En este caso, su declive es tan definitivo empíricamente como es positivo normativamente. Pero encontramos también formulaciones más moderadas donde el argumento es que nacionalismo y metafísica, lejos de estar obsoletos, deben comprenderse ahora de forma más compleja: el nacionalismo ya no es la forma principal de organización social y política de la modernidad, así como la metafísica ya no ofrece un fundamento sólido a las tareas de la filosofía. Aun así, ambas son aún presentes y relevantes en el mundo contemporáneo. El desafío es justamente comprender nacionalismo y metafísica a partir de las transformaciones sociales e intelectuales del presente.

Es esta segunda perspectiva la que me parece más fructífera, puesto que, en mi opinión, la literatura especializada no ha explorado aún de forma sistemática las relaciones entre nacionalismo y cosmopolitismo. Desde el lado del nacionalismo, puede decirse que el libro de Hans Kohn (2008) The Idea of the Nation inaugura, en la década de 1940, lo que es ahora el campo bien consolidado de los estudios sobre nacionalismo. Mucha agua ha corrido bajo el puente desde aquel intento temprano por comprender la idea moderna de nación. Industrialismo, capitalismo, democracia, etnicidad, colonialismo, xenofobia, guerra, burocracia estatal, idiomas nacionales, esfera pública, religión, factores generacionales $y$, por cierto, las clases sociales. Todos estos conceptos han sido usados como el factor preponderante que permite explicar el surgimiento y las características principales del sistema moderno de estados nación (Anderson, 1991; Bendix, 1964; Billig, 1995; Delanty y Kumar, 2006; Gellner, 1997; Giddens, 1985; Hobsbawm, 1994; Hroch, 1985; Llobera, 1994; Smith, 1986; Tilly, 1992; Wimmer, 2002). Sin embargo, el cosmopolitismo no aparece de manera significativa en ninguna de estas explicaciones. Incluso si la globalización de tales factores es tomada en consideración para explicar la expansión mundial del nacionalismo moderno, el cosmopolitismo está ausente para quienes estudian los procesos de formación nacional.

La situación en la literatura sobre cosmopolitismo es, en alguna medida, distinta (Delanty, 2009, 2012; Fine, 2007; Harvey, 2009; Kendall et al., 2009; Pendenza, 2014; Turner, 2006; Vertovec y Cohen, 2002). En el caso de la sociología, por ejemplo, los argumentos de Ulrich Beck $(2000,2006)$ llaman la atención por su lenguaje hiperbólico, pero reflejan también la visión preponderante sobre el nacionalismo entre quienes se ocupan del cosmopolitismo. 
En vez de explorar expresamente las relaciones entre ambos, el argumento se presenta en forma unilateral: la «apertura» cosmopolita y su optimismo normativo se definen por oposición a la "clausura» regresiva que caracterizaría al nacionalismo. Puesto que antecede el surgimiento del nacionalismo moderno y del sistema de estados nación, la relevancia del cosmopolitismo se refiere, fundamentalmente, a la cuestión de en qué medida es capaz de mantener bajo control las tendencias chovinistas, xenófobas y provincianas del nacionalismo. El cosmopolitismo queda, así, definido por oposición e intento de superación del sentido de pertenencia comunitaria a algo anticuado del que nos habla el nacionalismo. Incluso si se la define en términos cívicos, la nación es aún vista como un factor fundamental en los excesos del imperialismo europeo, a la vez que como un marco normativo demasiado débil como para proteger los derechos de distintas minorías étnicas, religiosas y, por cierto, nacionales al interior de los propios estados. La visión preponderante entre los pensadores cosmopolitas contemporáneos es que hemos de estar agradecidos de vivir en un mundo donde el nacionalismo puede comprenderse como una cuestión del pasado: históricamente, porque la globalización, el multiculturalismo y la migración han hecho caducar las imágenes tradicionales de la nación; desde un punto de vista normativo, porque el particularismo en que se sustentan las ideas modernas de cultura y etnicidad hacen imposible que la nación desempeñe un rol positivo en la renovación de las fuentes normativas de la democracia global (Held, 1995) ${ }^{2}$.

En la literatura reciente, un camino especialmente fructífero para explorar las relaciones entre nacionalismo y cosmopolitismo ha sido planteado por Gerard Delanty (2006). Su argumento es doble: por un lado, Delanty sostiene que la idea de nación tiene una dimensión universal, puesto que ofrece una «visión de la comunidad humana» de alcance general y que ha demostrado ser capaz de generar apoyo en una amplísima variedad de grupos humanos y contextos socioculturales. Por otro lado, él explica que los desarrollos cosmopolitas en el mundo contemporáneo se suceden tanto en el interior como más allá de los propios estados nación (Delanty, 2006: 358). Nacionalismo y cosmopolitismo no se relacionan entonces como los puntos opuestos de un continuo, sino que de manera mucho más compleja. Es justamente esta idea la que me propongo explorar en detalle en las páginas que siguen.

\section{$-\mathrm{II}$}

Quisiera iniciar mi recorrido revisando dos casos del período fundacional de las ciencias sociales en que estas relaciones sí fueron abordadas explícitamente. A inicios del siglo xx, y en el contexto de la expansión del nacionalismo

2. Un acercamiento liberal y democrático al nacionalismo puede usar estas mismas razones para criticar un cierto elitismo en el cosmopolitismo contemporáneo: el sujeto cosmopolita se caracterizaría por su capacidad financiera para establecer una distancia social y cultural con las expresiones más regresivas o extremas del nacionalismo (Calhoun, 2002, 2012). 
moderno en la Europa de la época, Émile Durkheim y Friedrich Meinecke se hicieron cargo explícitamente de este asunto. Durkheim y Meinecke comparten el interés por la institucionalización de las ciencias humanas, sociales y políticas, en Francia y Alemania respectivamente, y consideraron su trabajo como una contribución a un proyecto nacional superior y más amplio. En esa tarea, ambos asumieron que era fundamental estudiar el rol de las ideas y de los valores cosmopolitas en la formación de las identidades y de las estructuras nacionales. Las similitudes entre ambos se detienen ahí, dado que, políticamente, sus posiciones son del todo opuestas: Durkheim era judío, políticamente progresista y partidario acérrimo de las reformas de la Tercera República francesa, mientras que Meinecke fue un activo político de derecha en Alemania y profesó tendencias abiertamente antisemitas.

A juicio de Meinecke, el cosmopolitismo moderno y el principio de nacionalidad de los estados nación se constituyen mutuamente durante el siglo de las luces. En su opinión, esta conexión habrá de disolverse en algún momento en el futuro próximo - de hecho, tal disolución habría comenzado ya-, pero no hay dudas de que se ha tratado de una relación necesaria. Desde sus inicios en el siglo XVIII, comenta Meinecke, la idea moderna de la autonomía nacional «estuvo emparentada y entrelazada con ideas que amenazaban con asfixiarla». Lejos de oponerse a ella, las ideas universales del cosmopolitismo ilustrado eran igualmente constitutivas para esta generación: nacionalismo y cosmopolitismo se alimentan mutuamente en este período (Meinecke, 1970: 69). La individuación cultural de una nación, expresada, por ejemplo, por los movimientos del romanticismo filosófico y artístico, es un proceso lento pero inexorable que, en el caso específico de Alemania, ha comenzado tardíamente en relación con las otras potencias europeas. Meinecke describe entonces una tendencia que comienza con una concepción indiferenciada de humanidad, que en Europa tiene sus orígenes en la cristiandad, pero que se despliega crecientemente en nociones de individualidad cultural y autonomía política que encontrarían expresión «verdadera» en un estado que se define de manera únicamente nacional. Se trata, en este caso, de una tendencia que se despliega teleológicamente y cuya culminación se expresaría en la unificación de comunidades culturales en sus propios estados - tendencia que se probaría "definitivamente» en la unificación alemana de 1870 (Meinecke, 1970: 48)—. Pero incluso la fundación tardía del estado nación alemán mantiene una deuda importante con la pretensión universalista original con que se fundaron las ideas de nación y de humanidad durante la Revolución Francesa: «el sentimiento nacional alemán auténtico y más alto incluye el ideal cosmopolita de una humanidad más allá de la nacionalidad [...] es "antialemán ser puramente alemán”» (Meinecke, 1970: 21). A pesar de los excesos de su nacionalismo político y su rechazo a la orientación normativa del cosmopolitismo, su explicación del surgimiento del estado nación moderno considera de manera importante el rol de las ideas cosmopolitas. El marco de referencia universalista del cosmopolitismo es una dimensión fundamental del contexto cultural en el que surgen las nociones modernas de nación, nacionalismo y estado nación. Este argumento es espe- 
cialmente relevante en razón de la forma que han adoptado las posiciones de corriente principal en sociología: Meinecke rechaza el argumento de que el desarrollo de las naciones y los estados nación pueda explicarse «internamente» o «desde dentro»; por el contrario, su surgimiento y expansión a lo largo y ancho del planeta han de ser explicados como procesos efectivamente globales (Chernilo, 2011: 159-183).

Por su parte, Durkheim estuvo igualmente interesado en estudiar las relaciones entre nacionalismo y cosmopolitismo, pero usa otros procesos históricos como referencia, a la vez que sus justificaciones normativas son contrarias a las de Meinecke. Poco después del inicio de la Primera Guerra Mundial, y tomando como referencia los escritos de Heinrich Treitschke, Durkheim (1915) se queja amargamente de que un sentido de misión civilizatoria tan arrogante y chovinista se haya apoderado de la nación alemana y la haya conducido a una guerra de agresión sin precedente. La concepción del nacionalismo que Durkheim favorece se centra entonces en un rechazo a tendencias expansionistas que, a su juicio, se han demostrado ya obsoletas: el imperialismo europeo es ya un proyecto del siglo pasado. Las naciones progresistas han de concentrarse en la justicia social que ha de inspirar su organización interna. El objetivo político de este argumento es sin duda nacionalista, puesto que estamos analizando un panfleto escrito expresamente en apoyo al esfuerzo de guerra francés y que abusa de referencias antialemanas. Pero aun en ese contexto, Durkheim insiste sin descanso en que nacionalismo y cosmopolitismo van siempre de la mano. En el contexto más académico de sus clases y de sus textos científicos, él los define como dos formas de motivación de la conducta humana que son igualmente importantes y están íntimamente entrelazados: uno se enfoca internamente en la nación propia y el otro mira al mundo exterior y adopta como referencia una noción universalista de humanidad. A su juicio, el patriotismo y el cosmopolitismo no están en competencia, sino que han de entenderse como dos «sentimientos igualmente elevados» (Durkheim, 1992: 106).

Puesto que, en su opinión, no hay oposición entre las ideas de nación y de humanidad, el desarrollo de las sociedades modernas puede entenderse como el proceso de constitución de una pluralidad de patrias que se lleva a cabo mediante la ampliación y la posterior centralización burocrática de las unidades políticas medievales. La patria es fundamental para la vida moderna, puesto que ella ha de convertirse en el punto focal de la vida política. Pero la idea de patria no puede entonces fundarse en nociones de cultura primigenia o de un tipo étnico común, sino que ha de concentrarse en el desarrollo de vínculos políticos compartidos que miren hacia el futuro. Una patria verdadera necesariamente está relacionada con la idea universalista de humanidad, pues sólo ello evita el surgimiento de la peor clase de chovinismo nacionalista. Dice, entonces, Durkheim (1992: 109):

Si cada estado se asigna como tarea esencial no el crecer, el extender sus fronteras, sino el adecuar mejor su autonomía, el invitar a una vida moral más y más alta a la mayor cantidad posible de sus miembros, desaparecerá toda contra- 
dicción entre la moral nacional y la moral humana [...] Hemos visto que es en este sentido como avanza la evolución. Cuanto más concentran las sociedades sus fuerzas internamente, hacia su vida interior, más se sustraen también de los conflictos que oponen cosmopolitismo y patriotismo [...] las sociedades han de dedicar su amor propio no en ser las más grandes o las más ricas, sino en ser las más justas, las mejor organizadas y las que tienen la mejor constitución moral. Sin duda, no estamos aún en un momento en que tal patriotismo haya de reinar sin contrapeso, si es que tal momento ha de llegar alguna vez.

Esta breve presentación de ambos pensadores de inicios del siglo pasado intenta justificar mi afirmación inicial de que es pertinente y plausible explorar con mayor detención las relaciones entre nacionalismo y cosmopolitismo. Por un lado, las deficiencias de la posición política de Meinecke se explican justamente porque él equipara cosmopolitismo con un universalismo plano y sin distinciones internas; por el otro, si bien la posición de Durkheim es más sofisticada, su llamado a la «unidad nacional» a partir de la idea del enemigo externo puede ser considerado ingenuo, idealista o incluso ideológico. Asimismo, no es del todo adecuado afirmar que el único valor normativo de la nación depende de su compromiso con el universalismo del cosmopolitismo. El argumento filosófico de este artículo, por lo tanto, sostiene que, para dar cuenta de las relaciones entre nacionalismo y cosmopolitismo, debemos estudiar los momentos de universalidad y particularidad que hay en cada uno de ellos.

\section{$-\mathrm{III}-$}

Una vez establecida la conexión histórica entre nacionalismo y cosmopolitismo, me interesa ahora formular sus relaciones en términos estrictamente conceptuales. Comienzo descartando las nociones simétricas de que el nacionalismo puede concebirse únicamente en referencia al particularismo (étnico o cultural) y de que el cosmopolitismo está únicamente enfocado en una idea universal de humanidad que se expresa a costa de cualquier forma particular. Por el contrario, me interesa interrogar los momentos particular y universal que están presentes en ambos. Una versión más fuerte de este argumento, pero que no puedo justificar adecuadamente aquí, es que las relaciones entre nacionalismo y cosmopolitismo son expresión moderna de la dialéctica entre lo universal y lo particular (Chernilo, 2011, 2013a). Por un lado, el universalismo moderno surge de la articulación antes que de la superación de los particulares a partir del cual necesariamente se constituye: es un universalismo que se construye, está en permanente redefinición y no puede simplemente imponerse «desde arriba». Por el otro, la conciencia particularista moderna surge a partir de la coexistencia de distintos grupos y es ella misma expresión de la incipiente condición global de la modernidad: el particularismo hace explícitas las diferencias socioculturales, pero se basa en el fundamento común, que, por lo general, se mantiene implícito, de la pertenencia común a la especie humana.

Para los efectos de la discusión que sigue, defino el nacionalismo como un referente sociocultural fundamental del mundo moderno. El nacionalismo es, 
posiblemente, la forma más importante con que distintos grupos humanos, a lo largo y ancho del planeta, movilizan políticamente sus identidades socioculturales. Es a partir de esa movilización política que se favorece «naturalmente» una tendencia hacia la creación de estados "propios»" ${ }^{3}$. El momento particular del nacionalismo radica en su capacidad de proveer un sentido de clausura su capacidad para establecer una frontera entre "ellos» $\mathrm{y}$ "nosotros»—. Por su parte, el momento universal del nacionalismo reside no solo en el apoyo que ha recibido en todo el mundo durante los últimos 150 años, sino también en su conexión con un principio general de autodeterminación colectiva. El cosmopolitismo lo defino como el horizonte normativo fundamental a través del cual las sociedades modernas articulan ideas de paz y justicia que son válidas para todos los seres humanos sin exclusión. Lo fundamental del universalismo cosmopolita radica en una visión amplia de la humanidad que rechaza cualquier barrera que ponga restricciones a tal pretensión de inclusividad. Por su parte, el momento particular del cosmopolitismo se ha de concentrar en la autorreflexión sobre «nuestras» tradiciones, y las dudas sobre "nuestras» creencias más sentidas, puesto que ambas son parte ineludible de la vida moderna en un contexto global. En el contexto contemporáneo de una modernidad global, todo grupo y cultura humana es expresión de la unidad diversa de nuestra especie: la negación de tal estatus humano ya no es normativamente posible.

La tabla que se presenta a continuación expresa mi argumento general de forma esquemática. Los cuadrantes identifican los aspectos más importantes del

\begin{tabular}{|c|c|c|}
\hline & Particularismo & Universalismo \\
\hline \multirow[t]{2}{*}{ Nacionalismo } & $\begin{array}{l}\text { La nación es el referente identitario } \\
\text { más importante de la modernidad. }\end{array}$ & $\begin{array}{l}\text { Apoyo global a las instituciones } \\
\text { internacionales. }\end{array}$ \\
\hline & $\begin{array}{l}\text { La nación acepta e incluso } \\
\text { promueve heterogeneidad inter- } \\
\text { na, pero solo en la medida en que } \\
\text { su posición de privilegio no se ve } \\
\text { amenazada. }\end{array}$ & $\begin{array}{l}\text { Afirmación general del principio de } \\
\text { autodeterminación colectiva que se } \\
\text { expresa en la conformación de un } \\
\text { estado propio. }\end{array}$ \\
\hline \multirow[t]{3}{*}{ Cosmopolitismo } & $\begin{array}{l}\text { El cosmopolitismo favorece la } \\
\text { autorreflexión sobre «nuestras» tradi- } \\
\text { ciones y las dudas sobre «nuestras» }\end{array}$ & $\begin{array}{l}\text { Una noción inclusiva de humanidad } \\
\text { que se basa en atributos humanos } \\
\text { compartidos. }\end{array}$ \\
\hline & & \multirow{2}{*}{$\begin{array}{l}\text { Los seres humanos son portado- } \\
\text { res de derechos en tanto seres } \\
\text { humanos. }\end{array}$} \\
\hline & $\begin{array}{l}\text { El cosmopolitismo debe estar dis- } \\
\text { ponible para que «el otro» esté en lo } \\
\text { correcto como expresión de la idea } \\
\text { de humanidad común. }\end{array}$ & \\
\hline
\end{tabular}

3. Este argumento, me parece, es aceptable tanto desde una posición "primordialista», que sostiene que las naciones anteceden y pujan por crear estados propios, como desde la posición "modernista», donde los estados anteceden e inventan sus naciones. Si bien he argumentado que la posición modernista me parece más convincente (Chernilo, 2010:37-62), lo que me interesa destacar aquí es el acoplamiento específicamente moderno entre la formación sociocultural «nación» y el aparato burocrático «estado». 
nacionalismo y del cosmopolitismo, tanto en su dimensión universal como en la particular. Excepto en casos extremos como el genocidio, donde una orientación universalista tiende a desaparecer completamente, mi argumento es que las cuatro dimensiones son igualmente importantes, tanto en la conceptualización del nacionalismo como del cosmopolitismo ${ }^{4}$. En lo que resta del artículo, me propongo explicar en detalle cada uno de estos cuatro momentos.

\section{Nacionalismo/Particularismo}

La mayor parte de las teorías sobre nacionalismo del siglo xx —étnicas y cívicas, modernistas y primordialistas - enfatizan correctamente el hecho de que la nación ha sido la forma moderna más exitosa para crear sentidos de identidad y pertenencia. Durante los últimos doscientos años, la nación ha devenido efectivamente en un referente social, cultural y político de la modernidad. Parte crucial de este éxito es la capacidad de las naciones para proveer estabilidad en un contexto de cambio social constante y acelerado. Cuando las relaciones familiares, religiosas, lingüísticas, geográficas y económicas son todas sujeto de transformaciones simultáneas e incluso contradictorias, la nación ha sido capaz de posicionarse como el punto focal que permite hacer comprensible tanto cambio: la tradición parece quedar resguardada, la estabilidad parece reestablecerse, la pertenencia parece quedar garantizada y se nos asegura que el futuro es aún predecible. Fortalecida en su asociación con un aparato burocrático, los estados nación devienen en la formación sociocultural y política que se presenta como la única capaz de garantizar el bienestar social. Con ello, todas las otras formas de identidad personal y colectivo pueden quedar subordinadas a la identidad nacional. De los estados nación, se espera que puedan responder a nuestras demandas colectivas por integración social, política, cultural y emocional. Puesto que la identidad nacional se transforma en un elemento tan fundamental de la identificación personal y colectiva, el nacionalismo se ha transformado en el principio normativo y político con mayor capacidad de movilización de la modernidad. Allí parece radicar el componente central de lo que podemos denominar el «embrujo de las naciones»; a saber, el hecho de que son exitosas en la creación de un sentido de clausura y pertinencia, tanto en condiciones democráticas, como también bajo regímenes dictatoriales e incluso totalitarios. En una altísima variedad de contextos históricos, étnicos, sociales o religiosos, se trata siempre del intento de proveer certidumbre en contextos de cambio social acelerado.

Esta característica del nacionalismo queda reflejada en la literatura académica que no termina por ponerse de acuerdo sobre en qué consiste el núcleo definitorio de la nación. Pero no hay nada nuevo en esta dificultad, como bien lo entendía ya Max Weber cuando afirmaba que, «dada su alta carga emocional», la nación «es uno de los términos más problemáticos» en el naciente voca-

4. Las situaciones de genocidio son ocurrencia común en la modernidad (Spencer, 2012), pero su carácter extremo y normativamente repudiable radica precisamente en la desaparición completa del horizonte universalista al que me estoy refiriendo. 
bulario conceptual de la sociología (Weber, 1978: 395). Sostiene Weber que el problema de definir una nación es tan complejo que él no cree que pueda lograrse de manera unívoca. Se lamentaba de que no solo la idea de pueblo, sino también el lenguaje, la etnicidad, la clase, un tipo antropológico común, el linaje compartido y, por supuesto, una cultura común hayan sido todas propuestas como el elemento definitorio de la nación. A pesar de ello, ninguna consigue realmente tal objetivo (Weber, 1970: 171-8). En vez de entender este hecho como una fuente incurable de frustración conceptual, me parece que podemos interpretar las dificultades de las que habla Weber como expresión de una característica constitutiva de las naciones modernas: tal «opacidad» de las naciones es una de las características que nos permite justamente explicar su éxito (Chernilo, 2007, 2010). Distintos grupos humanos tienen visiones distintas sobre qué es una nación "en general» (así como también sobre cuál es el rasgo distintivo de la nación propia) y allí radica justamente una de las grandes virtudes de la combinación entre nación y estado en la modernidad: su capacidad para crear una apariencia de homogeneidad justamente a partir del hecho de que sus prácticas y sus representaciones públicas son extremadamente diversas. Lejos de ser un defecto, esta opacidad es fuente de credibilidad y apoyo para la nación y le permite parecer tan natural y ubicua.

Un aspecto fundamental del particularismo de la nación es, entonces, que su sentido de clausura no acepta que su posición de privilegio como referente sociocultural sea puesto en cuestión. La religión, la clase, la etnicidad o la ideología, todas, han sido vistas como una «amenaza» contra esa posición de privilegio de la nación, pero ella no puede dejar que ese desafío sea percibido como una afrenta al valor primordial de la unidad nacional. Pero si tales referencias socioculturales alternativas no amenazan la posición de privilegio de la nación y, por el contrario, aceptan una posición subordinada de forma permanente, entonces tal diversidad y heterogeneidad nacional no es solo tolerada, sino que tambiés es promovida e incluso celebrada como una de sus grandes fortalezas. En la medida en que no se definan explícitamente como «antinacionales» o se las asuma implícitamente como tales, todas las formas alternativas de afiliación colectiva pueden ser integradas como parte de la diversidad «natural» o «saludable» de la nación. La gran mayoría de las naciones modernas han tenido que acomodar muchísima mayor variabilidad interna de la que están dispuestas a reconocer abiertamente. $\mathrm{O}$, para decirlo más claramente, el éxito de una nación depende del equilibrio precario e inestable entre su heterogeneidad interna real, puesto que ello es central en su apelación a los diversos sectores de la sociedad, y el hecho de que su primacía se mantenga incuestionada como referente identitario fundamental: la nación debe seguir siendo el referente que, en último término, regula cualquier otra forma de identidad colectiva. Las diferencias internas son aceptables y pueden incluso ser favorecidas como fortalecedoras de la integración nacional, en la medida en que no parezca poner en jaque su viabilidad como entidad autónoma. Del mismo modo, distintas formas de exclusión —expresadas paradigmáticamente en la idea de «traición a la patria» - es el precio que se paga cuando se sobrepasa ese umbral. El par- 
ticularismo de la nación sólo acepta diferencias internas en la misma medida en que no tolera amenazas, ni percibidas ni reales, a su «unidad». De más está decirlo, las consecuencias de tal amenaza son siempre reales para sus víctimas ${ }^{5}$.

\section{Cosmopolitismo/Universalismo}

La idea cosmopolita temprana de un "ciudadano del mundo», que se define por oposición a la idea del ciudadano de una comunidad política específica, nos habla ya del núcleo universalista que es central a toda orientación cosmopolita (Hammond, 1951). Al movimiento estoico de la filosofía griega clásica, se le atribuye comúnmente haber sido el primero en ofrecer una perspectiva cosmopolita de este tipo, y la conexión posterior entre estoicismo y el desarrollo de lealtades no locales en el contexto del Imperio romano está bien acreditada (Arendt, 1998: 17; Windelband, 1957: 303-19). Lo primero que me interesa destacar en relación con la orientación universalista del cosmopolitismo es que ella no surge a partir de la tensión entre la «realidad» de comunidades históricas concretas y visiones abstractas o «ideales» que, por definición, son imposibles de realizar efectivamente. Este cosmopolitismo temprano debe entenderse más bien como un acto de imaginación social y política que intenta construir formas nuevas y diversas de asociación y pertenencia (Koselleck, 2004: 150-190). La imaginación cosmopolita ofrece, así, una crítica anticipada al presupuesto modernista de que el sentido de pertenencia puede asegurarse únicamente a partir de dinámicas de clausura y exclusión (Bartelson, 2009).

El núcleo universalista del cosmopolitismo, la idea de que todos los seres humanos sin excepción son miembros de la misma especie, es él mismo un desarrollo transhistórico y transcultural que está disponible en las distintas religiones mundiales (Voegelin, 2000). Al mismo tiempo, en la filosofía occidental, la orientación universalista del cosmopolitismo ha sido preservada primordialmente en la tradición del derecho natural (Chernilo, 2013a; D'Entrèves, 1970). Así, la recuperación que, hacia fines del siglo xviII, Kant (1999) hace de estas doctrinas cosmopolitas originales da nuevos bríos a esa orientación universalista primigenia. Sus ideas de derecho cosmopolita y derecho a la hospitalidad, así como su rechazo a la institución de los ejércitos permanentes, son todas intuiciones normativas que apuntan a dar concreción a tres principios morales fundamentales:

1. Los seres humanos son poseedores de derechos en tanto seres humanos y no en razón de su membresía a grupos o asociaciones específicas.

2. Instituciones como los ejércitos permanentes son esencialmente inmorales, porque tratan la vida humana únicamente como un medio.

5. El caso reciente de Edward Snowden es ilustrativo: la acusación de traición se relaciona, precisamente, con el argumento de que sus acciones ponen en riesgo la seguridad y por ello, en último término, la existencia de la nación. Ver Scheuerman (2014) para un análisis de este caso desde el punto de vista de su justificación como forma de desobediencia civil. 
3. No le debemos lealtad automática a nuestro lugar de nacimiento o residencia ${ }^{6}$.

Además de estos argumentos normativos, Kant señala también que hay tendencias empíricas que hablan en favor de una emergente constelación cosmopolita: el crecimiento del comercio internacional habría de favorecer relaciones interestatales pacíficas, el surgimiento de una sociedad civil global haría que las experiencias de guerra y sufrimiento en una parte del planeta se sientan como propias en otros rincones de la Tierra, y la organización de la vida cívica bajo un orden legal republicano haría menos probable que los ciudadanos apoyasen acciones militares costosas y chovinistas. Podemos decidir ignorar las intuiciones normativas de Kant a partir del argumento de que sus predicciones históricas se han probado erradas: el comercio internacional ha usado la violencia como mecanismo privilegiado para abrir nuevos mercados coloniales; los llamados de ayuda humanitaria global se hacen de forma cínica y se abusa de ellos, y la apelación a sentimientos nacionalistas ha contribuido a dar apoyo a innumerables campañas militares. Aun así, las ideas de Kant son relevantes, puesto que las experiencias de racismo, colonialismo y militarismo de los siglos anteriores nos demuestran precisamente la importancia de tales intuiciones normativas. Y, por supuesto, ellas siguen estando a la base de las justificaciones que usamos para rechazar normativamente tales prácticas e instituciones.

El universalismo del cosmopolitismo no requiere ni promueve la idea de una polis única, centralizada u homogénea, pero sí está a favor de la universalidad de los derechos humanos (Donnelly, 2003). En un lenguaje más filosófico, este es también un llamado para el reconocimiento y la protección legal del conjunto de capacidades antropológicas que hacen posible la vida social: todos los seres humanos están igualmente dotados con las destrezas que les permiten crear y recrear la vida social; todas nuestras identidades particulares, que son, por cierto, contingentes, socialmente construidas y culturalmente heredadas, se basan en un principio compartido y universal de pertenencia a la especie humana. La pluralidad de identidades con que nos reconocemos mutuamente solo está disponible porque somos la clase de seres (humanos) capaces de desarrollar tal pluralidad de identidades; solo de otros seres humanos decimos que tienen un abanico amplio de identidades culturales y sociales. Más problemática desde el punto de vista sociológico, mas no necesariamente en perspectiva filosófica, es la afirmación de que ideas de naturaleza humana hacen de fundamento implícito de las proposiciones universalistas: el universalismo cosmopolita parece requerir el presupuesto de que todos los seres humanos están naturalmente dotados con un conjunto de capacidades cuyo despliegue solo es posible socialmente, en compañía de

6. La tesis de Kant de que ningún pueblo tiene derecho automático sobre porciones específicas de territorio es, por tanto, una crítica y no una declaración de apoyo a las empresas coloniales de la época (Muthu, 2003). 
otros $^{7}$. El universalismo de las ideas de naturaleza humana no depende de si habremos, finalmente, de encontrar un elemento orgánico que ha de definir «de una vez y para siempre» nuestra humanidad común, pero sí se espera que pueda ofrecer un fundamento más sólido a partir del cual justificar instituciones, expectativas y diversas posiciones normativas: todo aquello que tiene lugar en la sociedad puede evaluarse desde el punto de vista de si favorece o restringe el desarrollo de nuestras capacidades y potenciales humanos. Esto explica, además, la tensión permanente entre proposiciones descriptivas y normativas que es omnipresente en las ciencias sociales y políticas modernas: las proposiciones normativas descansan, en último término, en concepciones antropológicas de lo humano que, por lo general, se han mantenido implícitas (Chernilo, 2014a) ${ }^{8}$.

\section{Cosmopolitismo/Particularismo}

El problema de las raíces imperiales de la identidad europea contemporánea es central para caracterizar el momento particular de cosmopolitismo. Un argumento posible aquí es que el discurso cosmopolita de las últimas dos décadas está directamente relacionado con la forma en que los estados europeos intentan dar nuevos bríos a sus permanentes ambiciones coloniales (Braidotti, Hanafin y Blaagaard, 2013). El cosmopolitismo es visto, en este caso, como la actualización — más o menos cínica - del legado colonial de Europa bajo las banderas también tradicionales de la paz, la democracia, la libertad y el humanismo (Douzinas, 2000). Por su parte, podemos referirnos positivamente al cosmopolitismo desde el punto de vista de su apelación identitaria: en qué medida una identidad cosmopolita ha de contribuir a articular un nuevo proyecto para Europa que ponga fin a varios siglos de guerras internas en el continente. Si el cosmopolitismo ha de desempeñar un rol práctico o político en el mundo contemporáneo, debe entonces abandonar sus aspiraciones globales y concentrarse solo en Europa (Beck y Grande, 2007). El cosmopolitismo queda, así, presentado como una suerte de ideología no oficial de la Unión Europea y ha de reflejar los desafíos que la unión enfrenta en los más variados ámbitos: visiones opuestas sobre sus principios fundamentales, inequidad eco-

7. En su enfoque de las capacidades, Martha Nussbaum se refiere al conjunto de propiedades humanas que hacen posible la socialidad (2006): la satisfacción de necesidades corporales en relación con el mundo exterior, un sentido de identidad colectiva e individual, la habilidad para diseñar cursos racionales de acción, el pensamiento creativo, la necesidad emocional de desarrollar vínculos con otros seres humanos y, por supuesto, el lenguaje. En sociología, una posición de este tipo ha sido articulada por Margaret Archer (2000). Para una formulación en términos de filosofía primera, véase la idea de «biología filosófica», de Hans Jonas (2001).

8. Desde el punto de vista del desarrollo de herramientas metodológicas para la sociología y las ciencias sociales, este universalismo cosmopolita apunta al desarrollo de una empatía humana antes que sociocultural: el despliegue de formas de comprensión y, por cierto, de solidaridad que se basan en nuestras experiencias humanas comunes -felicidad, amor y tristeza, justicia, indiferencia e injusticia, admiración, extrañeza y horror - tanto o más que en ideas de cultura o experiencias compartidas (Chernilo, 2010: 133-153, 2011: 47-74). 
nómica, déficit democrático, presiones relativas a la inclusión y a la exclusión de nuevos estados miembros. Por un lado, queda abierta la pregunta de si el proyecto cosmopolita será efectivamente capaz de aunar esas demandas con un «éxito similar» a la forma en que la nación lo hizo en los dos siglos anteriores. Por el otro, sabemos que, en Europa, las poblaciones se relacionan de forma cada vez más compleja con varias identidades nacionales, étnicas, lingüísticas y religiosas, y que este pluralismo es cada vez más importante, tanto para las identidades individuales de sus habitantes, como para las identidades colectivas de los propios estados: desde la migración que proviene de las antiguas colonias hasta la propia migración intraeuropea, es cada vez más difícil pretender que las identidades nacionales son, efectivamente, unívocas?

Una formulación más general sobre el momento particularista del cosmopolitismo puede plantearse de la siguiente manera: todos los seres humanos tienen la capacidad de desarrollar identidades múltiples que se sobreponen y se intersectan de forma, si no impredecible, al menos contingente. Parte de este argumento parece resonar con la idea de «interseccionalidad» que está ahora en boga en la sociología anglosajona (Walby et al., 2012; Yuval-Davis, 2006). El éxito del interseccionalismo se basa en su capacidad para ilustrar el carácter estructural de ciertos condicionantes específicos (género, clase, etnicidad). Pero, desde la perspectiva que estoy desarrollando en este artículo, tal énfasis estructural presenta el problema de que tiende a esencializar las identidades que estudia y se concentra exclusivamente en la reproducción de las relaciones de dominación. Es sin duda cierto que determinadas identidades y posiciones sociales desventajosas se retroalimentan y, por ello, reproducen las condiciones de inequidad, pero el argumento me parece debe hacerse de manera más general y enfatizar también la forma más fluctuante e incluso autónoma en que individuos y grupos negocian sus distintas identidades. El momento particular del cosmopolitismo que me interesa reivindicar aquí se expresa en el hecho de que solo los propios individuos y grupos pueden jerarquizar sus distintas identidades.

El particularismo del cosmopolitismo apunta, entonces, al descentramiento de la nación como el referente identitario más importante de la modernidad. Si bien las identidades nacionales siguen siendo fundamentales, hemos de entenderlas solo como una entre las muchas que las personas construyen, adoptan, aceptan y rechazan a lo largo de sus vidas. La pluralidad de identidades e intereses de los individuos no conoce de jerarquías naturales y se rebela frente a aquellas que les son impuestas: todas nuestras identidades son subjetivamente importantes, justamente porque es esa combinación idiosincrática la que constituye nuestra «identidad personal». Dado que la posición de privilegio en relación con las identidades no nacionales es el valor más importante para el particularismo nacionalista, esta dimensión enfatiza justamente la «derrota definitiva» de ese nacionalismo: vivimos crecientemente en un mundo donde

9. En Chernilo (2011: 103-122), aparece una crítica tanto empírica como normativa a esta posición que restringe la relevancia del cosmopolitismo únicamente al contexto europeo. 
conviven múltiples identidades en un mismo individuo y en el interior de la misma nación.

Hay, así, un momento de autorreflexión que deviene fundamental para establecer las condiciones en que es posible dejar de tomar como inevitables o naturales nuestras propias prácticas, valores y afiliaciones: el particularismo cosmopolita debe tomarse en serio el pluralismo de la modernidad global. Quisiera ensayar, en este contexto, una idea que tomo prestada de la defensa de Hans-Georg Gadamer frente a la acusación de relativismo contra su programa hermenéutico. Dice Gadamer que la formulación metodológica que mejor describe su posición es la idea de que debemos «escuchar al otro en la creencia de que puede estar en lo correcto" (Grodin, 2003: 250). La apertura del cosmopolitismo a la particularidad del otro debe interpretarse como la incertidumbre ineludible frente al hecho de que ninguna tradición está ya disponible como forma automática de legitimación. En una relación dialógica en que las posiciones del hablante y del oyente se intercambian en múltiples ocasiones y, con ello, cambia también el peso de la prueba de tener que demostrar quien está en lo cierto. Este particularismo cosmopolita se hace evidente también en que «el otro» no es nunca, aquí, un "otro radical». Se trata siempre de un ser humano que está, asimismo, embarcado en el proceso desafiante de intentar comprender sobre sus propias preconcepciones. Ahí radica también la contribución estrictamente cosmopolita a la autocrítica de la historia europea: internamente, en relación con el carácter autodestructivo de sus nacionalismos, y externamente, en relación con el tratamiento explotador que recibieron aquellas partes del globo que cayeron bajo su dominio.

\section{Nacionalismo/Universalismo}

Quisiera empezar esta última sección haciendo referencia a una tendencia histórica muy simple. Cuando, en 1945, se fundaron las Naciones Unidas, se establecieron con el apoyo de 51 estados provenientes de todos los continentes y con el poderío económico y la orientación ideológica más diversos. Desde entonces, la organización ha experimentado un crecimiento sostenido: 76 estados miembros en 1955, 116 en 1965, 144 en 1975, 159 en 1985, 185 en 1995,192 en 2002 y 193 desde $2011^{10}$. Este crecimiento se explica, por cierto, en razón de varios procesos geopolíticos globales - la descolonización de África y del sudeste asiático en las décadas de 1950 y 1960, así como la desaparición de la Unión Soviética y su área de influencia a inicios de la década de 1990-. Pero la tendencia indica también el éxito del estado nación como referente sociopolítico fundamental de la modernidad. Y si bien, para las potencias europeas, no todos los pueblos fueron originalmente candidatos aptos para la «autodeterminación nacional», dominios coloniales y naciones subdesarrolladas en todo el mundo se dieron cuenta rápidamente del potencial emancipador que subyace a esta pretensión universalista de autodetermina-

10. Fuente: http://www.un.org/en/members/growth.shtml. 
ción nacional (Manela, 2007). La membresía a toda clase de organizaciones internacionales depende directamente de tal condición estatal nacional $-\mathrm{O}$, al menos, de la reclamación de tal condición- y se ha transformado, así, en una apelación normativa general al derecho a la vida colectiva autónoma. La nacionalidad es entendida como un atributo esencial de los seres humanos cuando se trata de la organización de la vida en común ${ }^{11}$.

No hay, por cierto, nada natural o necesario en el hecho de que nacionalidad y estatalidad hayan devenido en los criterios fundamentales de membresía a estas organizaciones internacionales - mucho menos en el hecho de que algunas naciones y no otras hayan perdurado en el tiempo (Billig, 1995)-. La nación debió ser construida como el lugar donde las distintas lealtades e identidades pudieron encontrar un foco común - y el rol de las organizaciones burocráticas estatales en este proceso está bien estudiado (Mann, 1993)—. En términos de su relación con el cosmopolitismo, Norbert Elias ha investigado cómo las noblezas europeas mostraron un interés temprano en identidades no nacionales porque tenían mayor cercanía en sus gustos, costumbres e intereses económicos y políticos con las noblezas de otros países que con las clases bajas sobre las que ejercían dominio. A su juicio, el «sentimiento prerrevolucionario del "nosotros" ", que es propio de las relaciones entre las distintas clases altas europeas con anterioridad a la modernidad, era posiblemente "más intenso» que el que sentían por "las clases inferiores de su propio país». Así, su apego hacia el «estado propio no tenía aún el carácter de un apego hacia la nación». Es sólo en la medida en que el propio aparato estatal crece que "las élites dominantes, y con el tiempo también estratos más amplios, adquirieron el sello específico del sentimiento nacional» (Elias, 1996: 143-144).

Elias explica las relaciones entre una perspectiva cosmopolita y una nacional a partir del surgimiento del sistema moderno de clases sociales. Y ese es también el argumento de Eric Hobsbawm (1994) en relación con las clases populares, puesto que, en su caso, el desarrollo de la idea moderna de democracia nacional se vio originalmente reforzado en el despliegue de un conjunto de redes transnacionales e internacionales. Así, durante los siglos XVIII y XIX, el internacionalismo obrero no solo tuvo una relación positiva con los movimientos de democratización nacional, sino que ambos también sumaron fuerzas en la causa común de derribar las barreras que restringían el derecho a voto y la promoción de regímenes impositivos más progresivos. Los programas políticos con orientación de clase, tanto como los que favorecieron agendas nacionales,

11. El principio 3 de la Declaración de Naciones Unidas sobre los Derechos del Niño estipula que todos los niños y niñas tienen, desde su nacimiento, derecho a un nombre y a una nacionalidad (http://www.un.org/es/comun/docs/?symbol=A/RES/1386\%20(XIV)). Una asociación tan estrecha entre nombre y nacionalidad es normativamente problemática, porque asume implícitamente que la nacionalidad es tan importante desde el punto de vista de la identidad colectiva como el nombre lo es desde el punto de vista de la identidad personal. Pero, al mismo tiempo, se trata de un argumento que habla a favor de la universalidad de la apelación nacional en la modernidad. Sobre las relaciones entre nombre e identidad, son interesantes las reflexiones de Charles Taylor (1989: 525). 
buscaron el apoyo de las clases trabajadoras y la pequeña burguesía a partir de su interés común por ampliar la participación política y por una distribución más equitativa de los costos económicos de la formación de los estados. Los movimientos democráticos desempeñaron, así, un papel fundamental en el establecimiento de las democracias nacionales: en perspectiva histórica, la legitimidad de la democracia moderna está íntimamente asociada a la legitimidad de la democracia nacional. Es solo a contar del último tercio del siglo xIX que las agendas políticas nacional(istas) y las agendas obreras entraron crecientemente en conflicto.

Una dimensión central del momento universal del nacionalismo es, entonces, la capacidad autogeneradora del derecho colectivo a la autodeterminación: una vez que los grupos deciden o reconocen que su posibilidad de autodeterminación radica en una aspiración nacional, es imposible negar legitimidad normativa a tal reclamación. Como bien lo explicó ya Rousseau, la autodeterminación moral individual y la autodeterminación política colectiva se presuponen y se requieren mutuamente. $Y$ si bien ambas formas de autodeterminación no precisan teóricamente de la nación, en la práctica, ella devino en el espacio social donde tal conexión podría, al menos, intentar desplegarse. Al mismo tiempo, el principio de igualdad ante la ley, así como la presión creciente por el acceso igualitario a las prestaciones estatales, apuntalan el momento universal del nacionalismo: la procedimentalización burocrática, así como la división de funciones y de poderes de la actividad estatal, sostienen el horizonte universalista de la acción estatal.

\section{$-\mathrm{IV}-$}

Para concluir, podemos volver a la obra de Habermas para reflexionar sobre el doble dilema filosófico que se nos presenta cuando intentamos capturar las tensiones entre universalismo y particularismo a la luz de los problemas del nacionalismo y del cosmopolitismo. Por una parte, la idea de nación parece requerir la equiparación, a todas luces problemática, entre una idea genérica o cívica de pueblo y una noción más exclusiva de comunidad (étnica, religiosa o cultural). Tal equiparación entre el potencial genérico de un ser humano que toma decisiones autónomas y los derechos y deberes específicos del ciudadano de una comunidad particular genera dificultades, puesto que:

Mientras que la nación «querida» de los ciudadanos constituye la fuente de la legitimación democrática, la nación «nacida», compuesta por quienes pertenecen étnicamente a un pueblo, se ocupa de la integración social [...]. En las categorías conceptuales del Estado nacional, se encuentra incrustada la tensión entre el universalismo de una comunidad jurídica igualitaria y el particularismo de una comunidad con un destino histórico. (Habermas, 1999: 91)

El asunto al que apunta Habermas es el fundamento simultáneamente universal y particular de la nación: inclusión y exclusión son parte igualmente relevante del principio nacional de autodeterminación democrática. Pero 
encontramos, además, un segundo dilema normativo que se expresa en los textos fundacionales de la democracia política moderna: la Declaración Americana de Independencia y la Declaración Universal de los Derechos del Hombre y del Ciudadano, que surge a partir de la Revolución Francesa. El dilema radica, aquí, en cómo hacer compatible el principio democrático de la autodeterminación colectiva con el requerimiento de infalibilidad normativa que se expresa en su rol para asegurar la protección efectivamente inalienable de ciertos derechos. Nuevamente en palabras de Habermas:

[n]o es ninguna casualidad que los derechos humanos adoptaran, ya en el contexto de aquellas primeras constituciones, una forma concreta, a saber: como derechos fundamentales que han de ser garantizados en el marco de un ordenamiento jurídico nacional. Sin embargo, tienen, tal como parece, un doble carácter: como normas constitucionales, gozan de validez positiva, pero, como derechos que le corresponden a cada persona como ser humano, se les adscribe, al mismo tiempo, una validez suprapositiva. (Habermas, 1999: 174)

En el siglo xxI, no necesitamos ya recordatorio de que las democracias se equivocan y que tales errores se pueden pagar a un precio muy alto en términos de vidas humanas. $\mathrm{O}$, para decirlo de otra forma, ninguna democracia es lo suficientemente democrática como para garantizar la adecuación normativa de sus decisiones más importantes. Si bien no puedo desarrollarlo aquí en detalle, el problema filosófico que queda así instalado es el dilema fundacionalista de toda pretensión universalista. En el caso de la dimensión universalista del nacionalismo, la pregunta puede plantearse de la siguiente manera: ‘en qué medida la naturaleza abierta e indeterminada de los procesos de toma de decisiones democráticas ha de ofrecer garantía suficiente de que los derechos básicos de individuos y minorías serán respetados aun contra la voluntad de la mayoría nacional? ¿Cómo se justifican normativamente los límites a la autodeterminación colectiva democrática? ${ }^{12}$.

Los estados nación no han sido la única forma en que se han institucionalizado los desarrollos normativos más importantes de la modernidad, pero su relevancia no puede pasarse por alto en la implementación de la separación entre moralidad y legalidad o entre autonomía pública y privada. Al mismo tiempo, la relación entre autodeterminación colectiva y autodeterminación individual es condición fundamental de su legitimidad democrática: nadie puede ser obligado a ser feliz, pero nadie puede serlo tampoco en aislamiento o separado de la sociedad. Hemos visto que, al menos durante buena parte del siglo XIX, un impulso inclusivo estuvo a la base de la idea universal de autodeterminación colectiva legítima: decisiones vinculantes son aquellas adoptadas por todos los potenciales involucrados. Si bien la nación pareció, o al menos pretendió durante un tiempo, cumplir el papel de contenedor de tales deman-

12. He discutido algunas de estas cuestiones en relación con la filosofía moral de Kant y la teoría social de Habermas en Chernilo (2013a: 126-131, 2013b). Ver también Specter (2010: 178-179) en lo relativo al problema del fundacionalismo de la teoría legal de Habermas. 
das, es preciso reconocer que su horizonte de racionalidad tuvo un horizonte cosmopolita desde sus inicios (Brunkhorst, 2014). La modernidad global en que vivimos ya no deja lugar a dudas de que tal impulso universalista no queda contenido en el interior de las fronteras nacionales. Al mismo tiempo, ello nos ofrece la oportunidad para repensar aquellas tendencias que han socavado el potencial universalista que estaba presente en sus orígenes.

\section{Referencias bibliográficas}

Albrow, M. (1996). The Global Age. Cambridge: Polity Press.

Anderson, B. (1991). Imagined communities. Londres: Verso.

Archer, M. S. (2000). Being human: The problem of agency [en línea]. Cambridge: Cambridge University Press. <http://dx.doi.org/10.1017/CBO9780511488733>.

Arendt, H. (1998). The human condition. Chicago: The University of Chicago Press.

Bartelson, J. (2009). Visions of world community. Cambridge: Cambridge University Press.

Beck, U. (2000). «The cosmopolitan perspective: Sociology of the second age of modernity». British Journal of Sociology, 51 (1), 79-105.

- (2006). Cosmopolitan vision. Cambridge: Polity Press.

Beck, U. y Grande, E. (2007). Cosmopolitan Europe. Cambridge: Polity Press.

BENDIx, R. (1964). Nation-building and citizenship: Studies of our changing social order. Nueva York y Londres: John Wiley \& Sons.

Billig, M. (1995). Banal Nationalism. Londres: Sage.

Braidotti, R.; Hanafin, P. y Blaagaard, B. (eds.) (2013). After cosmopolitanism. Londres: Routledge.

Brunkhorst, H. (2014). Critical theory of legal revolutions: Evolutionary perspectives [en línea]. Londres: Bloomsbury. $<$ http://dx.doi.org/ http://dx.doi.org/10.5040/9781501302121>.

Calmoun, C. (2002). "The class consciousness of frequent travellers: Towards a critique of actually existing cosmopolitanism». En: Vertovec, S. y Cohen, R. (eds.). Conceiving cosmopolitanism: Theory, context, and practice. Oxford: Oxford University Press.

- (2012). "Cosmopolitan liberalism and its limits». En: Robertson, R. y Krossa, A. (eds.). European Cosmopolitanism in Question. Basingstoke: Palgrave. $<$ http://dx.doi.org/10.1057/9780230360280.0010>.

CAstells, Manuel (1996). The rise of the network society. Oxford: Blackwell.

Chernilo, D. (2007). A social theory of the nation-state: The political forms of modernity beyond methodological nationalism. Londres: Routledge.

- (2010). Nacionalismo y cosmopolitismo: Ensayos sociológicos. Santiago: Universidad Diego Portales.

- (2011). La pretensión universalista de la teoría social. Santiago: Lom.

- (2013a). The natural law foundations of modern social theory: A quest for universalism [en línea]. Cambridge: Cambridge University Press. $<$ http://dx.doi.org/10.1017/CBO9780511842511>.

- (2013b). "Jürgen Habermas: Modern social theory as postmetaphysical natural law». Journal of Classical Sociology [en línea], 13 (2), 254-73. <http://dx.doi.org/10.1177/1468795X13477294>. 
- (2014a). «The idea of philosophical sociology». British Journal of Sociology [en línea], 65 (2), 338-357. $<$ http://dx.doi.org/10.1111/1468-4446.12077>.

- (2014b). «Concepciones de sociología en la sociología constitucional contemporánea». Economía y Politica, 1 (2), 105-134.

Delanty, G. (2006). «Nationalism and cosmopolitanism: The paradox of modernity». En: Delanty, G. y Kumar, K. (eds.). Handbook of nations and nationalism. Londres: Sage. $<$ http://dx.doi.org/10.4135/9781848608061>.

- (2009). The cosmopolitan imagination: The renewal of critical social theory. Cambridge: Cambridge University Press.

- (ed.) (2012). The Routledge handbook of cosmopolitanism Studies. Londres: Routledge. $<$ http://dx.doi.org/10.4324/9780203837139>.

Delanty, G. y Kumar, K. (eds.) (2006). The SAGE Handbook of Nations and Nationalism. Londres: Sage. $<$ http://dx.doi.org/10.4135/9781848608061>.

D’Entrèves, A. (1970). Natural Law. Londres: Hutchinson.

Donnelly, J. (2003). Universal human rights in theory and practice. Nueva York: Cornell University Press.

Douzinas, C. (2000). The End of Human Rights. Oxford: Hart.

Durkheim, E. (1915). Germany above all. París: Collin.

- (1992). Leçons de sociologie. París: Presses Universitaires de France.

Elias, N. (1996). The Germans. Cambridge: Polity Press.

FINE, R. (2007). Cosmopolitanism. Londres: Routledge.

Gellner, E. (1997). Nationalism. Londres: Weidenfeld \& Nicolson.

Giddens, A. (1985). The nation-state and violence. Cambridge: Polity Press.

Grodin, J. (2003). Hans-Georg Gadamer: A biography. New Heaven: Yale University Press.

Habermas, J. (1999). La inclusión del otro: Estudios de teoría política. Barcelona: Paidós.

- (2001a). The postnational constellation. Cambridge: Polity Press.

- (2001b). «Why Europe needs a constitution?». New Left Review, 11, septiembreoctubre, 5-26.

- (2003). «Interpreting the Fall of a Monument». Constellations, 10 (3), 364-70. $<$ http://dx.doi.org/10.1111/1467-8675.00339>.

- (2006). The divided West. Cambridge: Polity Press.

- (2014). «Plea for a constitutionalization of international law». Philosophy and Social Criticism, 40 (1), 5-12. $<$ http://dx.doi.org/10.1177/0191453713514838>.

Hammond, M. (1951). City-state and world state in Greek and Roman political theory until Augustus. Cambridge, Massachusetts: Harvard University Press.

Harvey, D. (2009). Cosmopolitanism and the geographies of freedom. Nueva York: Columbia University Press.

HeLD, D. (1995). Democracy and the global order: From the modern state to cosmopolitan governance. Cambridge: Polity Press.

Новsваwм, E. (1994). Nations and nationalism since 1780. Cambridge: Cambridge University Press.

Нroch, M. (1985). Social preconditions of national revival in Europe. Cambridge: Cambridge University Press. 
Jonas, H. (2001). The phenomenon of life: Towards a philosophical biology. Evanston: Northwestern University Press.

Kant, I. (1999). Political writings. Cambridge: Cambridge University Press.

Kendall, G.; Woodward, I. y Skrbis, Z. (2009). The sociology of cosmopolitanism. Londres: Palgrave Macmillan.

Koнn, H. (2008). The idea of nationalism: A study in its origins and background. New Brunswick: Transaction.

Koselleck, R. (2004). Futures past: On the semantics of historical time. Nueva York: Columbia University Press.

Llobera, J. (1994). The god of modernity: The development of nationalism in Western Europe. Oxford: Berg.

Manela, E. (2007). The Willsonian moment: Self-determination and the international origins of anticolonial nationalism. Nueva York: Oxford University Press.

Mann, M. (1993). The sources of social power. Vol. II. Cambridge: Cambridge University Press.

Meinecke, F. (1970). Cosmopolitanism and the national state. Princeton: Princeton University Press.

Muthu, S. (2003). Enlightenment Against Empire. Princeton: Princeton University Press.

Nussbaum, M. (2006). Frontiers of justice: Disability, nationality, species membership. Cambridge, Massachusetts: Harvard University Press.

Pendenza, M. (ed.) (2014). Classical sociology beyond methodological nationalism [en línea]. Leiden: Brill. <http://dx.doi.org/10.1177/0191453713514838>.

Robertson, R. y Krossa, A. (eds.) (2012). European Cosmopolitanism in Question [en línea]. Basingstoke: Palgrave. <http://dx.doi.org/10.1057/9780230360280>.

Scheuerman, W. (2014). "Whistleblowing as civil disobedience: The case of Edward Snowden». Philosophy and Social Criticism [en línea], 40 (7), 609-628. <http://dx.doi.org/10.1177/0191453714537263>

Scholte, J. A. (2000). Globalization: A critical introduction. Londres: Palgrave.

SMith, A. D. (1986). The ethnic origins of nations. Oxford: Blackwell.

Specter, M. (2010). Habermas: An intellectual biography. Cambridge: Cambridge University Press.

Spencer, P. (2012). Genocide since 1945. Londres: Routledge.

TAYLOR, C. (1989). The sources of the self: The making of the modern identity. Cambridge, Massachusetts: Harvard University Press.

Teubner, G. (2012). Constitutional fragments: Societal constitutionalism and globalisation. Oxford: Oxford University Press.

Tilly, C. (1992). Coercion, capital, and European states, AD 990-1992. Oxford: Blackwell.

Turner, B. S. (2006). «Classical sociology and cosmopolitanism: A critical defence of the social». British Journal of Sociology [en línea], 57 (1), 133-55. <http://dx.doi.org/10.1111/j.1468-4446.2006.00097.x>.

URRY, J. (2000). Sociology beyond societies. Londres: Routledge.

Vertovec, S. y Cohen, R. (eds.) (2002). Conceiving cosmopolitanism: Theory, Context, and Practice. Oxford: Oxford University Press.

Voegelin, E. (2000). «Order and history volume IV. The ecumenic age». En: The collected works of Eric Voegelin. Vol. 17. Columbia: University of Missouri Press. 
Walby, S.; Armstrong, J. y Stird, S. (2012). «Intersectionality: Multiple Inequalities in Social Theory». Sociology [en línea], 46 (2), 224-240. <http://dx.doi.org/10.1177/0038038511416164>.

Weber, M. (1970). «The Nation». En: Gerth, H. y Mills, C. W. (eds.). From Max Weber: Essays in Sociology. Londres: Routledge and Kegan Paul.

- (1978). Economy and society. Vol. 1. Londres: University of California Press.

Wimmer, A. (2002). Nationalist exclusion and ethnic conflict: Shadows of modernity [en línea]. Cambridge: Cambridge University Press. <http://dx.doi.org/10.1017/CBO9780511490415>.

Windelband, W. (1957). History of ancient philosophy. Dover: Dover Editions.

Yuval-Davis, N. (2006). «Intersectionality and Feminist Politics». European Journal of Women's Studies [en línea], 13 (3), 193-209. <http://dx.doi.org/ http://dx.doi.org/10.1017/CBO9780511490415>. 